\title{
Self-Activation of Cellulose: A New Preparation Methodology for Activated Carbon Electrodes in Electrochemical Capacitors
}

\author{
Clement Bommier ${ }^{\mathrm{a}}$, Rui Xu, ${ }^{\mathrm{b}}$ Wei Wang ${ }^{\mathrm{a}}$, Xingfeng Wang ${ }^{\mathrm{a}}$, David Wen ${ }^{\mathrm{a}}$, Jun $\mathrm{Lu}^{\mathrm{b}} *$ and Xiulei $\mathrm{Ji}^{\mathrm{a}}{ }^{\mathrm{a}}$ \\ a. Department of Chemistry, Oregon State University, Corvallis, Oregon, 97331, United States \\ b. Chemical Sciences and Engineering Division, Argonne National Laboratory, Lemont, Illinois \\ 60439, United States
}

Emails: Xiulei Ji, david.ji@ oregonstate.edu; Jun Lu, junlu@anl.gov

\begin{abstract}
Current synthetic methods of biomass-derived activated carbon call for a high temperature pyrolysis followed by either a chemical or physical activation process. Herein, we report a simple one-step annealing synthesis yielding a high surface area cellulose-derived activated carbon. We discover that simply varying the flow rate of Argon during pyrolysis enables 'self-activation' reactions that can tune the specific surface areas of the resulting carbon, ranging from $98 \mathrm{~m}^{2} / \mathrm{g}$ to values as high as $2600 \mathrm{~m}^{2} / \mathrm{g}$. Furthermore, we, for the first time, observe a direct evolution of $\mathrm{H}_{2}$ from the pyrolysis, which gives strong evidence towards an in situ self-activation mechanism. Surprisingly, the obtained activated carbon is a crumbled graphene nanostructure composed of interconnected sheets, making it ideal for use in an electrochemical capacitor. The cellulose-derived nanoporous carbon exhibits a capacitance of $132 \mathrm{~F} \mathrm{~g}^{-1}$ at $1 \mathrm{~A} \mathrm{~g} \mathrm{~g}^{-1}$, a performance comparable to the state-of-the art activated carbons. This work presents a fundamentally new way to look at the synthesis of activated carbon, and highlights the importance of a controlled inert gas flow rate during synthesis in general, as its contributions can have a very large impact on the final material properties.
\end{abstract}

\section{Keywords}

Pyrolysis; Cellulose; flow rate; self-activation; electrochemical capacitor 


\section{Introduction}

Annually around 50 million tons of forestry residues are produced as 'waste' in the U.S. alone [1]. This causes severe environmental concerns, such as a greater risk of forest fires and greenhouse gas emission [2]. While the biomass residues can be processed into valuable products, e.g., biofuels, high overhead costs, such as transportation from forest to processing sites, greatly decrease its economic viability [3-5]. Thus, it is of high urgency to discover scalable and affordable chemical methods that can convert biomass into valuable materials of even higher values. Along this line, activated carbon (AC) is one of the most promising materials that can be synthesized from biomass. With desirable properties, such as high surface area, chemical inertness, and good electrical conductivity, AC is a critical component for a plethora of applications, including energy storage [6-8], catalysis [9, 10], water/air purification [11$13]$, and gas storage $[14,15]$.

Currently, there are primarily two routes to synthesize ACs from biomass: "physical" activation and chemical activation. Physical activation requires two steps, where the first is pyrolysis and the following step is activation through gaseous etchants, e.g., $\mathrm{CO}_{2}$ or $\mathrm{H}_{2} \mathrm{O}$ steam [16-28]. In chemical activation, a mixture of biomass and activation reagents, such as $\mathrm{KOH}, \mathrm{B}(\mathrm{OH})_{3}, \mathrm{H}_{3} \mathrm{PO}_{4}, \mathrm{NaOH}$, or $\mathrm{ZnCl}_{2}$ is pyrolyzed before washing of the resulting carbon following activation [29-41]. Both physical and chemical activation methods lead to environmental consequences, and they involve multiple steps to obtain the final products, which drives the cost high. Thus, fundamentally more efficient methods are highly desirable.

Recently Luo et al. first discovered a one-step activation of cellulose under $\mathrm{NH}_{3}$ gas, where occur the simultaneous pyrolysis, activation and nitrogen doping [42]. However, $\mathrm{NH}_{3}$ gas is corrosive and relatively expensive. The question instead is whether AC can be prepared can be prepared through a simple control of the pyrolysis parameters of biomass, instead of consuming either chemical or physical activation reagents. The influence of pyrolysis parameters such as flow rate of inert gas, pyrolysis temperature and reaction duration on the synthesis of biochar, was investigated Lua et al. $[43,44]$ who 
were able to optimize the surface area up to $778 \mathrm{~m}^{2} \mathrm{~g}^{-1}$; though it should be noted that those reactions consumed $\mathrm{CO}_{2}$ gas - a physical activation agent. Similar studies on the effect of pyrolysis parameters obtain surface areas of $519 \mathrm{~m}^{2} \mathrm{~g}^{-1}$ and $707 \mathrm{~m}^{2} \mathrm{~g}^{-1}[45,46]$; but again the former work utilized a steam activation, while the latter study did not change the flow rate. While these early studies demonstrate that the high surface area, porous biochar can be synthesized through control of the pyrolysis parameters, they still were not able to demonstrate a one-step self-activation that produces a surface area comparable to traditional ACs.

Herein, we report that one-step pyrolysis of cellulose results in carbon surface area as high as $2600 \mathrm{~m}^{2} / \mathrm{g}$. Furthermore, we attribute the high surface area to the reaction between $\mathrm{H}_{2} \mathrm{O}$ released during carbonization and the derived carbon. We identify that the flow rate of the inert gas determines the $\mathrm{H}_{2} \mathrm{O}$ residence time and subsequently the levels of self-activation: a high flow rate prevents the self-activation due to a low residence time, while a low flow rate enhances the self-activation.

\section{Materials and Methods}

\section{Preparation of Activated Carbon}

We use filter paper (Whatman ${ }^{\mathrm{TM}}$ Type 1) comprising pure cellulose as the precursor. The pyrolysis is conducted under Argon at $1100^{\circ} \mathrm{C}$ for $2 \mathrm{~h}$ in the middle of a tube furnace with the inner diameter of 4.45 $\mathrm{cm}$. The furnace is purged under a high flow rate of Argon for $30 \mathrm{~min}$, before being switched to a desired flow rate. Flow rates of 10, 25, 50, 100 and $200 \mathrm{~cm}^{3} \min ^{-1}(\mathrm{CCM})$ are used. We refer to the samples according to respective flow rates, e.g., C-200 for the sample obtained under $200 \mathrm{CCM}$ of Argon.

\section{Material Characterizations}

Brunauer-Emmett-Teller (BET) surface area and Density Functional Theory (DFT) pore volume calculations are based on $\mathrm{N}_{2}$ sorption measurements on a Micromeritics TriStar II 3020 analyzer. XRD patterns are obtained by a Rigaku Ultima IV Diffractometer using Cu K $\alpha$ radiation $(\lambda=1.5406 \AA)$. Raman spectra are collected using a HR 800 LabRam HORIBA JOBIN YVON system with a $532.02 \mathrm{~nm}$ laser 
source. Scanning Electron Microscopy (SEM) images are recorded through a FEI Quanta 600 SEM. Transmission Electron Microscopy (TEM) images are collected with a FEI Titan 80-300 TEM. X-ray photoelectron spectroscopy (XPS) measurements are conducted on a Physical Electrons Quantera ESCA Microprobe with a focused Al K $\alpha$ X-ray $(1486.6 \mathrm{eV})$ source for excitation. The X-ray beam is a $25 \mathrm{~W}$, $100 \mu \mathrm{m}$ X-ray beam spot at the sample. The ion gun used is a standard Quantera ion gun, and the sputtered depth profiles are acquired using a $1 \mathrm{KeV}$ argon-ion beam rastered over a $3 \mathrm{~mm}$ x $3 \mathrm{~mm}$ area; and the binding energy scale is calibrated using the $\mathrm{Cu} 2 \mathrm{p}_{2 / 3}$ feature at $932.62(+/-) 0.05 \mathrm{eV}$ and $\mathrm{Au} 4 \mathrm{f}$ at 83.96 (+/-) $0.05 \mathrm{eV}$. Elemental analysis is conducted by a commercial company, Elemental Analysis Inc. Thermogravimetric Analysis (TGA) is conducted on a TA Instruments SDT-Q600 thermal analyzer. During TGA, the samples are heated in a 70- $\mu$ l alumina crucible under ultra-high pure Argon (50 CCM) from room temperature to $1100{ }^{\circ} \mathrm{C}$ at a ramp rate of $5{ }^{\circ} \mathrm{C} \mathrm{min}^{-1}$. The SDT-Q600 is also equipped with a mass spectrometer (MS) for detecting evolved gaseous species. Selected gaseous species, including $\mathrm{H}_{2}$, $\mathrm{H}_{2} \mathrm{O}, \mathrm{CO}$, and $\mathrm{CO}_{2}$, are monitored during cellulose pyrolysis.

\section{Characterization of Activated Carbons in Electrochemical Capacitors (ECs)}

The electrodes are prepared by mixing $80 \mathrm{wt} \%$ activated carbon, $10 \mathrm{wt} \%$ carbon black, C-45 (TimCal) and 10wt\% poly-1,1-difluoroethene (PVDF) binder in n-methyl-2-pyrrodilinone (NMP). The resulting paste is painted onto a current collector of stainless steel mesh and dried at $60^{\circ} \mathrm{C}$ in a vacuum oven. The active mass loading of the electrodes is $\sim 1 \mathrm{mg} \mathrm{cm}^{-2}$. Two-electrode capacitors are assembled in 2032 coin cells containing an aqueous electrolyte of $6 \mathrm{M} \mathrm{KOH}$. Galvanostatic cycling is conducted on a Maccor 3000 at $25^{\circ} \mathrm{C}$ at a current rate of $1 \mathrm{~A} \mathrm{~g}^{-1}$. Cyclic Voltammetry (CV) and Electrochemical Impedance Spectra (EIS) are obtained on a Bio-logic EC Lab VMP-3 under ambient conditions. Specific capacitance is obtained from data obtained during galvanostatic cycling using the Eq. 1

$$
C_{s}=\frac{4 I \cdot \Delta t}{m \cdot \Delta V}
$$

where $I$ is the current rate used and $m$ is the mass of the both electrodes. The equivalent series resistance (ESR) is obtained through Eq. 2 


$$
R_{E S R}=\frac{V_{\text {drop }}}{2 I} \quad \text { Eq. }(2)
$$

whereby $V_{d r o p}$ is the voltage drop at the onset of discharge and $I$ is the current rate used. Lastly electrochemical impedance spectra (EIS) of the symmetric ECs were conducted from $200 \mathrm{kHz}$ to $10 \mathrm{mHz}$.

\section{Results and Discussion}

The impact of Argon flow rate is evident from the $\mathrm{N}_{2}$ sorption measurements of the resulting nanoporous carbon (Figure 1, Table 1). As the flow rate decreases, the $\mathrm{N}_{2}$ absorption volume steadily increases. Using a low flow rate of $10 \mathrm{CCM}$ results in a specific surface area of as high as $2,600 \mathrm{~m}^{2} \mathrm{~g}^{-1}$ as opposed to only $98 \mathrm{~m}^{2} \mathrm{~g}^{-1}$ when a high rate of $200 \mathrm{CCM}$ is used. Performing a linear regression analysis of specific surface area and pore volume as a function of Argon flow rate yields an $\mathrm{R}^{2}$ of 0.961 and 0.965 , respectively, revealing a strong inverse correlation (Supplementary Figure S1 \& S2). Both linear regressions are performed on logarithm-transformed scales of flow rates. The high surface area and a short reaction time here are in sharp contrast to the $\mathrm{CO}_{2}$ activation of carbon that requires long reaction time, e.g., more than 15 hours, in order to yield a surface area of 2,400 $\mathrm{m}^{2} \mathrm{~g}^{-1}$ (Supplementary Figure S3). The pore size distributions show that the greatest portion of pore volume is attributed to pores between $2 \mathrm{~nm}$ and $20 \mathrm{~nm}$ (mesopores), followed by pores greater than $20 \mathrm{~nm}$ ('macropores'), and pores of less than $2 \mathrm{~nm}$ (micropores) (Table 1 and Figure 1c). Materials obtained at lower flow rates exhibit a much more even distribution of pores, which accounts for the switch from type $\mathrm{I}_{2}$ sorption isotherm at high flow rates to type I/IV isotherms at low flow rates. Lastly, in Figure 1d, we see that there is a linear correlation between the increase in pore volume and flow rate for all three types of pores; performing a linear regression of incremental pore volume versus flow rate yields $\mathrm{R}^{2}$ values of 0.96 for the micropores, 0.97 for the mesopores and 0.87 for the 'macropores' (Supplementary Figure S4). The results show that increases in porosity due to a lower flow rate in all types of pores are nearly linear as the flow rate is lowered. 


\begin{tabular}{|c|c|c|c|c|c|c|c|c|c|}
\hline \multirow{2}{*}{$\begin{array}{l}\text { Argon } \\
\text { Flow } \\
\text { Rate } \\
(\mathrm{CCM})\end{array}$} & \multirow{2}{*}{$\begin{array}{c}\text { BET } \\
\text { Surface } \\
\text { Area } \\
\left(\mathrm{m}^{2} \mathrm{~g}^{-1}\right) \\
\end{array}$} & \multirow{2}{*}{$\begin{array}{c}\text { DFT } \\
\text { Pore } \\
\text { Volume } \\
\left(\mathrm{cm}^{3} \mathrm{~g}^{-1}\right)\end{array}$} & \multicolumn{3}{|c|}{$\begin{array}{l}\text { Pore Size Distribution } \\
\text { volume }\left(\mathrm{cm}^{3} \mathrm{~g}^{-1}\right)\end{array}$} & \multirow{2}{*}{$\begin{array}{l}\text { Thickness } \\
\text { in (002) } \\
\text { direction }\end{array}$} & \multirow{2}{*}{$\begin{array}{l}\text { Empirical } \\
R \text { Value }\end{array}$} & \multirow{2}{*}{$\begin{array}{l}\mathrm{I}_{\mathrm{D}} / \mathrm{I}_{\mathrm{G}} \\
\text { Value }\end{array}$} & \multirow{2}{*}{$\begin{array}{l}\% \\
\text { Yield }\end{array}$} \\
\hline & & & $2<$ & $\begin{array}{l}2 \mathrm{~nm} \text { to } \\
20 \mathrm{~nm}\end{array}$ & $\begin{array}{c}> \\
20 \mathrm{~nm}\end{array}$ & & & & \\
\hline 10 & 2602 & 2.110 & 0.0435 & 1.665 & 0.562 & 2.82 & 1.22 & 1.13 & 1.6 \\
\hline 25 & 1637 & 1.156 & 0.0131 & 0.453 & 0.110 & 3.06 & 1.23 & 1.09 & 6.7 \\
\hline 50 & 598 & 0.453 & 0.0025 & 0.075 & 0.016 & 3.39 & 1.48 & 0.99 & 13.3 \\
\hline 100 & 337 & 0.226 & 0.0018 & 0.046 & 0.015 & 3.46 & 1.45 & 0.94 & 15.2 \\
\hline 200 & 98 & 0.062 & 0.0009 & 0.021 & 0.012 & 3.57 & 1.82 & 0.95 & 16.7 \\
\hline
\end{tabular}

Table 1. Results of BET surface area and DFT pore volume, as well as XRD and Raman results of the carbon materials obtained at different flow rates.

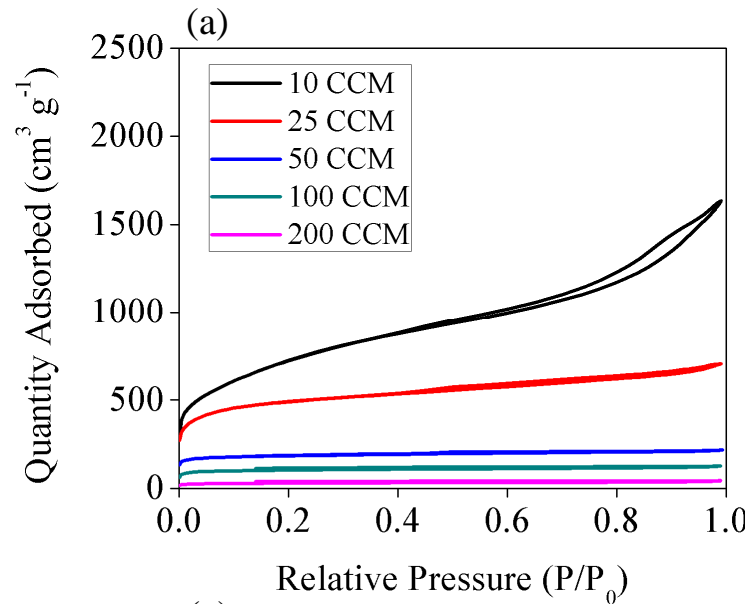

(c)

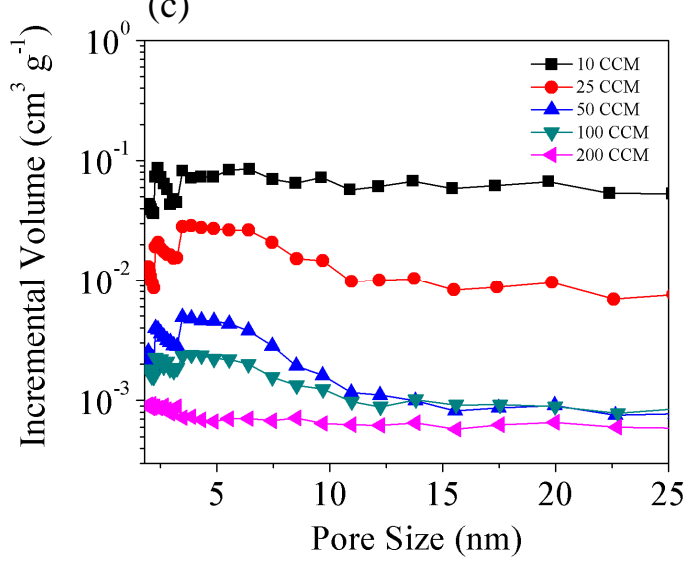

(b)

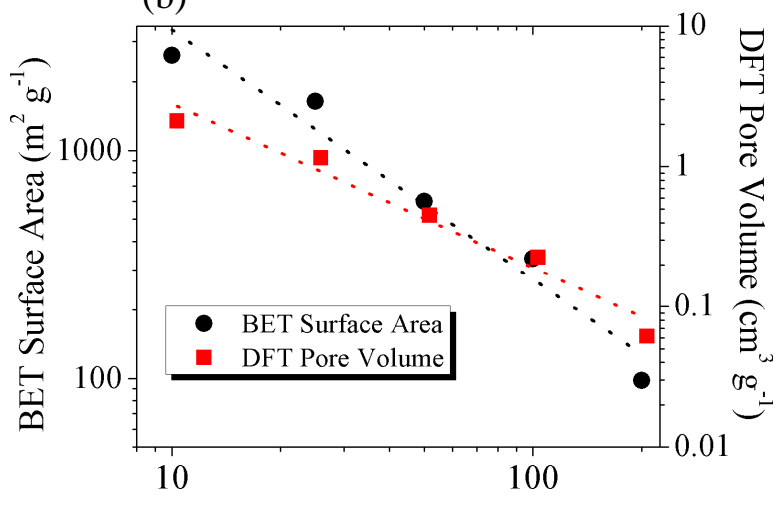

Argon Flow Rate $\left(\mathrm{cm}^{3} \mathrm{~g}^{-1}\right)$

(d)

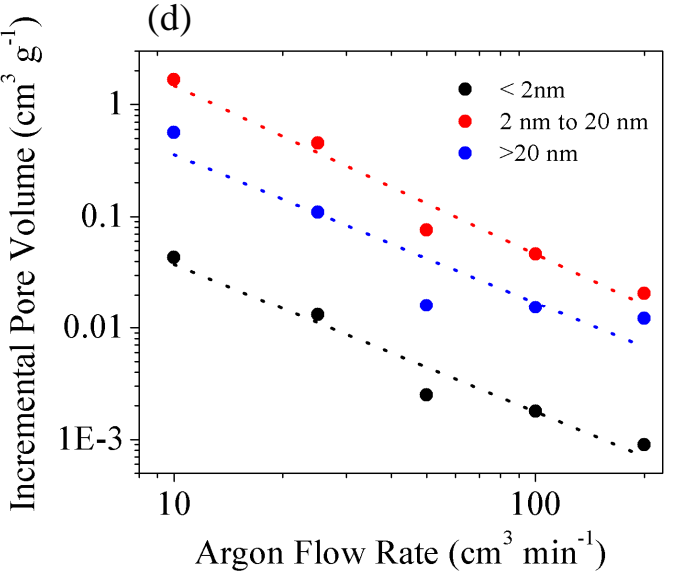

Figure 1. a) $\mathrm{N}_{2}$ sorption isotherms of different activated carbons, b) Dual plots of surface area and pore volume values versus Argon flow rates. c) Pore size distribution plot of the carbon materials d) Comparison of incremental volume of micropores, mesopores and macropores for the different activated carbon materials.

Following the $\mathrm{N}_{2}$ sorption measurements, we further characterized the structures of the obtained activated carbons. All of the obtained carbon samples exhibit an amorphous atomistic structure by 
displaying broad (002) and (100) peaks at $2 \theta$ angles of $23^{\circ}$ and $43^{\circ}$, respectively. The measured dspacings of (002) planes of the respective carbon samples do not vary much upon different flow rates, with most around $0.39 \mathrm{~nm}$. However, the short-range order along the $c$-axis of the synthesized carbons varies greatly upon different Ar flow rate as evident from the XRD profiles. Carbons obtained at high flow rates exhibit better resolved (002) peaks than those prepared at low flow rates (Figure 2a,c). Calculation by the Scherrer equation allows us to deduce the average thickness of the nanodomains along the $c$-axis, $\mathrm{L}_{\mathrm{c}}$ [47-49]. Dividing the nanodomain thickness by the $\mathrm{d}$-spacing estimates the average number of graphene layers, which decreases from 3.6 to 2.8 when the flow rate decreases from 200 to $10 \mathrm{CCM}$ (Table 1). When a linear regression of number of graphene layers vs. flow rate is performed, we obtain an $\mathrm{R}^{2}$ value of 0.948 , thereby showing that carbon nanodomains are thinned at low flow rates during pyrolysis (Supplementary Figure S5). The degrees of order along the c axis can be analyzed by $R$ calculations as well; $R$, an empirical parameter defined by Dahn et al., measures a ratio of (002) peak intensity, B, compared to the background, A, at the same diffraction angle (Supplementary Figure S6) [50]. This measurement allows quantifying the degrees of short-range order in an amorphous carbon, with higher $\mathrm{R}$ values implying a better degree of order. The $R$ values obtained correlate well with the nanoporosity induced in carbon, with high-surface-area carbon having an $R$ value of 1.2 but low-surfacearea carbon exhibiting an $R$ value greater than 1.8 (Table 1). Performing a linear regression analysis on flow rates vs. $R$ values and logarithm transformed data yields a $\mathrm{R}^{2}$ value of 0.817 (Supplementary Figure S7).

We further investigate the microstructure of the resulting carbons by TEM. As Figure 3a shows, C-200 with a specific surface area of $98 \mathrm{~m}^{2} \mathrm{~g}^{-1}$ contains randomly arranged curved graphene layers, described by the "house-of-cards" model [51-54]. On the other hand, C-10, also composed of curved graphene sheets, exhibits a much lower packing density of carbon sheets (Figure $3 \mathbf{b}$ ). This observation corroborates the XRD results that carbon activation occurs at low flow rate by thinning the carbon nanodomains along the c axis. SEM imaging is able to show some evidence of increased macroporosity 
when a low flow rate is used as opposed to high flow rate ones-though the scale of observation is too large to observe any features of the microstructure (Supplementary Figure S8).

Raman spectroscopy provides further structural insights of the amorphous carbon materials, particularly, the disorder degree in the graphene sheets (ab plane). A higher $\mathrm{I}_{\mathrm{D}} / \mathrm{I}_{\mathrm{G}}$, intensity of D-band at $1340 \mathrm{~cm}^{-1}$ over G-band at $1580 \mathrm{~cm}^{-1}$ that correspond to the defected $\mathrm{sp}^{2}$ and intact $\mathrm{sp}^{2}$ graphene, respectively, indicates a lower intactness of graphene. The $\mathrm{I}_{\mathrm{D}} / \mathrm{I}_{\mathrm{G}}$ ratios of the resulting carbon prove to be inversely correlated to the flow rate as well, with a maximum ratio of 1.10 at $10 \mathrm{CCM}$ and a minimum ratio of 0.94 at $200 \mathrm{CCM}$ (Figure 2b,c). It is evident that at a low flow rate, more defects in graphene sheets are generated. Considering that both the specific surface area/pore volume and $I_{D} / I_{G}$ ratios inversely correlate with the flow rate, a linear regression is performed for $I_{D} / I_{G}$ ratio as a function of both BET surface area and DFT pore volume. Both linear regressions show a strikingly high degree of correlation, with $\mathrm{R}^{2}$ values being of 0.971 and 0.940 . This implies an important message that porosity generation does occur in graphene planes. (Supplementary Figure S9 \& S10).

Up to this point, from the XRD, TEM and Raman results, it is evident that activation of the resulting carbon does occur through two distinct routes: and creating defects on the graphene sheets along ab plane. 
(a)

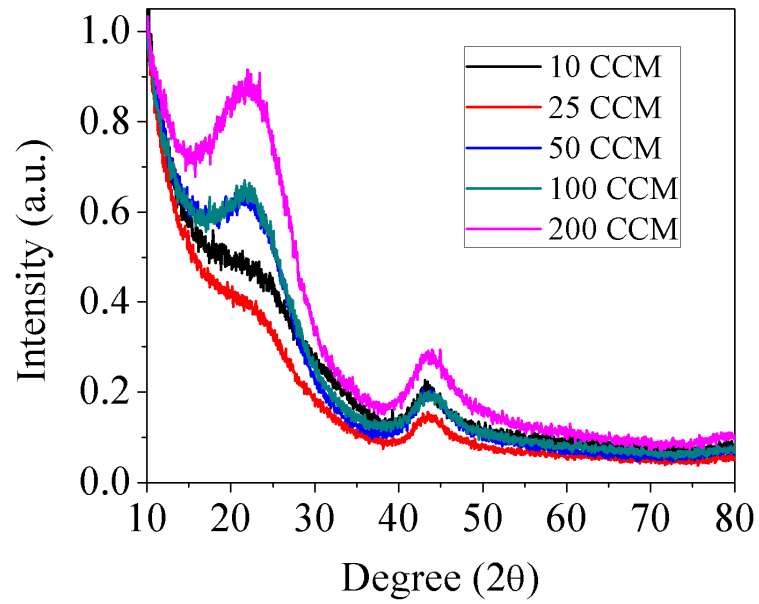

(b)

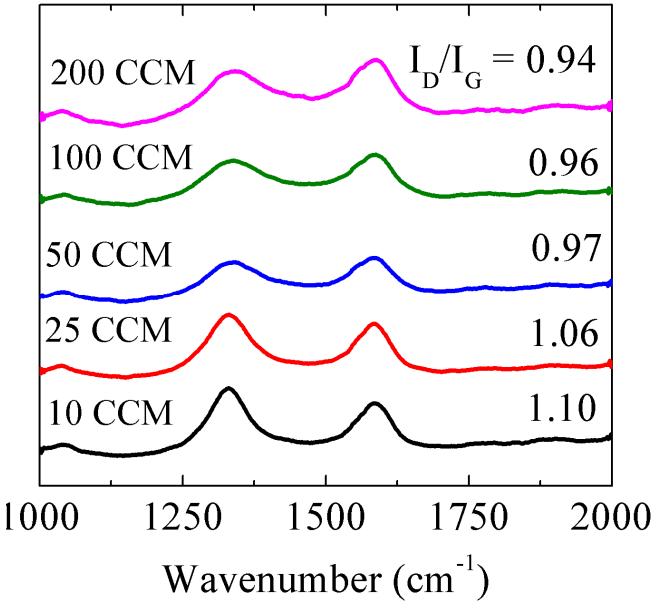

(c)

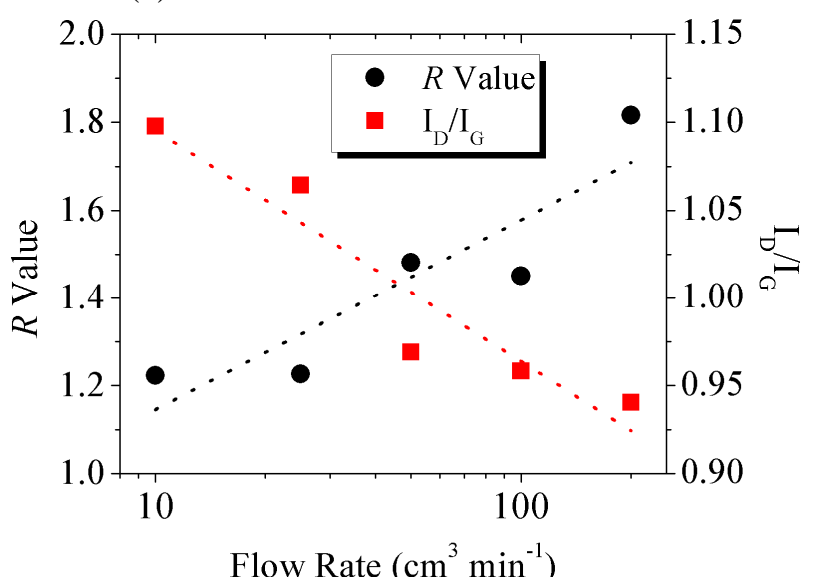

Figure 2. a, b) XRD patterns and Raman spectra of cellulose pyrolyzed for $2 \mathrm{~h}$ under different flow rates, c) Dual plot of the empirical $R$ value and $\mathrm{I}_{\mathrm{D}} / \mathrm{I}_{\mathrm{G}}$ ratios vs. flow rate of Argon. 
(a)

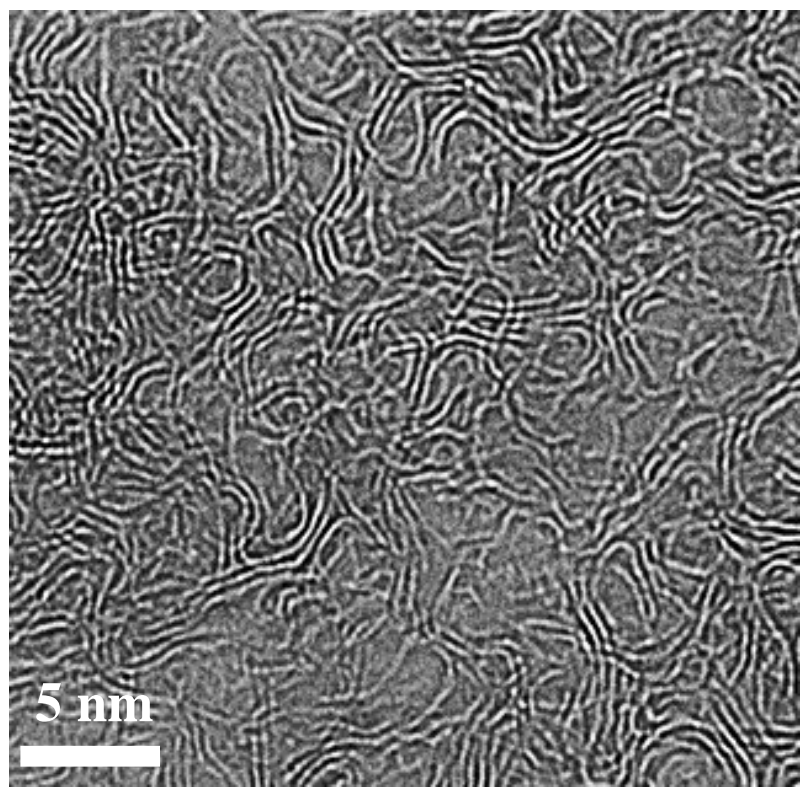

(b)

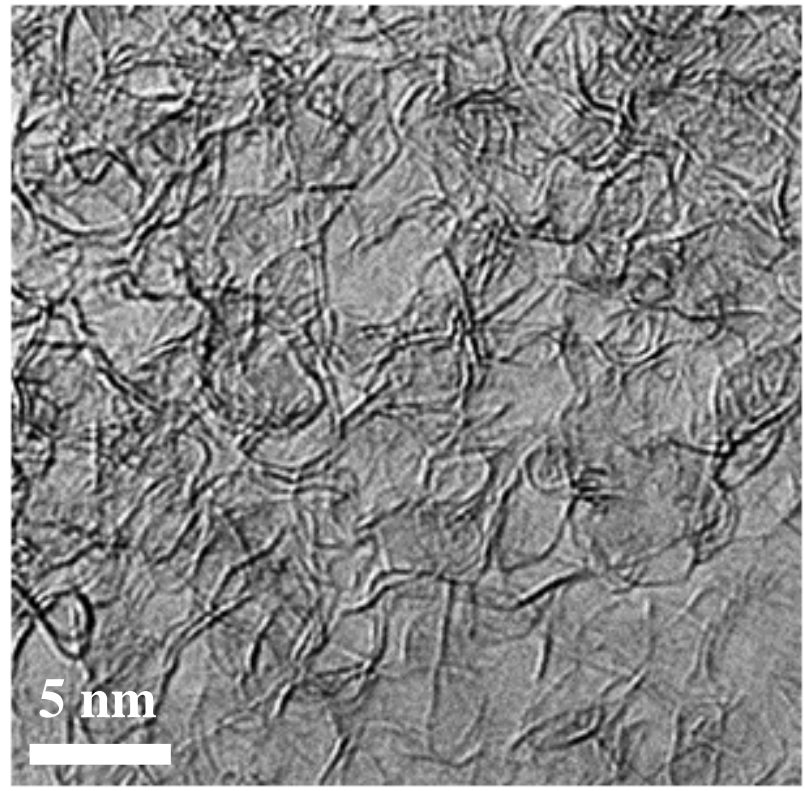

Figure 3. Typical TEM images showing the carbon microstructures of a) C-200 b) C-10. Both images show the randomly arranged curved graphene sheets and domains inside the samples.

To elucidate the mechanism behind the inverse correlation of the activation process and the Argon flow rates, we monitored the evolved $\mathrm{H}_{2}, \mathrm{H}_{2} \mathrm{O}, \mathrm{CO}$ and $\mathrm{CO}_{2}$ gases during pyrolysis via TGA-MS [55-60]. Although there are other larger volatile molecules possibly generated from cellulose pyrolysis, these four molecules are used here as markers to help understand the activation mechanism. As Figure 4a shows, the majority of the weight loss during cellulose pyrolysis occurs between $250{ }^{\circ} \mathrm{C}$ and $400{ }^{\circ} \mathrm{C}$ while the elimination of $\mathrm{H}_{2} \mathrm{O}$ along with minor evolution of $\mathrm{CO}$ and $\mathrm{CO}_{2}$ is observed. This process is often referred to as a primary reaction in cellulose pyrolysis. An important question to be answered here is how this pyrolysis process affects the overall physicochemical properties of the resulting carbon. Is the weight loss incurred from $250{ }^{\circ} \mathrm{C}$ and $400{ }^{\circ} \mathrm{C}$ inconsequential, or is it the sole reason for the self-activation reactions? 
To answer this question, we pretreated cellulose at $450^{\circ} \mathrm{C}$ and $600{ }^{\circ} \mathrm{C}$ for $6 \mathrm{~h}$, respectively, under Argon at a very high flow rate of 200 CCM. The pre-treatment aims to completely remove the 'possible' activation reagents generated at relatively low temperatures before the following high-temperature investigation. Furthermore, the high flow rate guarantees that little self-activation reactions take place during the pre-treatment. The two obtained samples are referred to as P-450 and P-600. After the pretreatment, P-450 and P-600 are further pyrolyzed at $1100^{\circ} \mathrm{C}$ for $6 \mathrm{~h}$ in under Argon at $10 \mathrm{CCM}$, resulting in surface areas of $1500 \mathrm{~m}^{2} \mathrm{~g}^{-1}$ and $730 \mathrm{~m}^{2} \mathrm{~g}^{-1}$, respectively (Supplementary Figure S11).

The above results provide two important insights. Firstly, it confirms that the species released below $450{ }^{\circ} \mathrm{C}$ and between $450{ }^{\circ} \mathrm{C}$ to $600{ }^{\circ} \mathrm{C}$ do contribute to the activation, considering that when a flow rate of $10 \mathrm{CCM}$ was used for the entire pyrolysis process, a final surface area of $2,600 \mathrm{~m}^{2} \mathrm{~g}^{-1}$ was obtained. Secondly, it is evident that above $600{ }^{\circ} \mathrm{C}$ there are still activation reagents released during cellulose pyrolysis, considering that C-200 sample has a final surface area of $98 \mathrm{~m}^{2} \mathrm{~g}^{-1}$. Activation at above $600{ }^{\circ} \mathrm{C}$ is supported by the TGA of P-600 as a significant percentage of weight loss occurs at temperatures beyond $600{ }^{\circ} \mathrm{C}$ (Figure $4 \mathbf{c} \& \mathbf{4 d}$ ). At pyrolysis temperatures below $600{ }^{\circ} \mathrm{C}$, it is known that cellulose polymer chains are dehydrolyzed and subsequently decomposed into a plethora of volatile molecules, also referred to as bio-fuels or bio-oils [61]. Such liquification reactions peak at around $550{ }^{\circ} \mathrm{C}$ and are mostly completed by $600{ }^{\circ} \mathrm{C}$ [62-64]. At temperatures greater than $600{ }^{\circ} \mathrm{C}$, the pyrolysis process begins to transition towards the release of smaller non-condensable gasses, such as $\mathrm{H}_{2}, \mathrm{H}_{2} \mathrm{O}, \mathrm{CO}$ and $\mathrm{CO}_{2}$ [65]. With this in mind, we thus propose that there are two possible self-activation reactions which can happen at higher temperatures.

$$
\begin{array}{ll}
C(s)+H_{2} O(g) \Leftrightarrow C O(g)+H_{2}(g) & E q .(3) \\
C(s)+C_{2}(g) \Leftrightarrow 2 C O(g) & E q .(4)
\end{array}
$$

The occurrence of these two activation reactions are supported by the TGA-MS results, as they show a stable evolution of $\mathrm{H}_{2} \mathrm{O}$ at higher temperatures with much higher pressure than $\mathrm{CO}$ and $\mathrm{CO}_{2}$. The $\mathrm{MS}$ results imply that the removal of residual hydrogen and oxygen atoms may form $\mathrm{H}_{2} \mathrm{O}$ at a wide range of temperatures during the pyrolysis process. Furthermore, there is a distinct peak of $\mathrm{H}_{2}$ evolution from 750 
${ }^{\circ} \mathrm{C}$ to $800{ }^{\circ} \mathrm{C}$ (Figure $\mathbf{4 b}$, c). This is consistent to the calculated temperature of $707{ }^{\circ} \mathrm{C}$, whereby the Gibbs free energy of the syngas formation reaction (Eq. 3) turns negative and thus the reaction becomes spontaneous. The $\mathrm{H}_{2}$ peak at above $700{ }^{\circ} \mathrm{C}$ may explain what the activation reaction is at high temperatures. Furthermore, the high $\mathrm{H}_{2}$ pressure leads to yet another possible activation reaction:

$$
C(s)+2 H_{2}(g) \Leftrightarrow \mathrm{CH}_{4}(g) \quad \text { Eq. (5) }
$$

Despite the possibility of self-activation via Eq. 4 \& Eq. 5, it is more likely that the syngas formation plays the primary role due to the vastly higher pressure of $\mathrm{H}_{2} \mathrm{O}$.

(a)

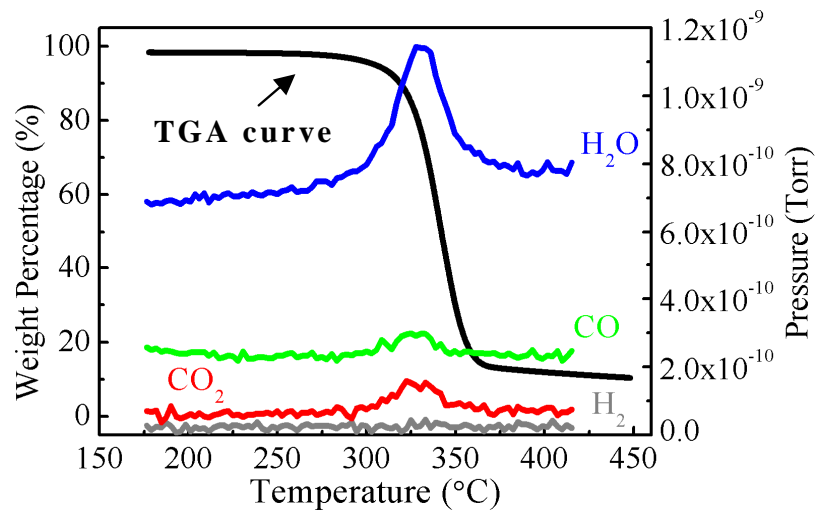

(c)

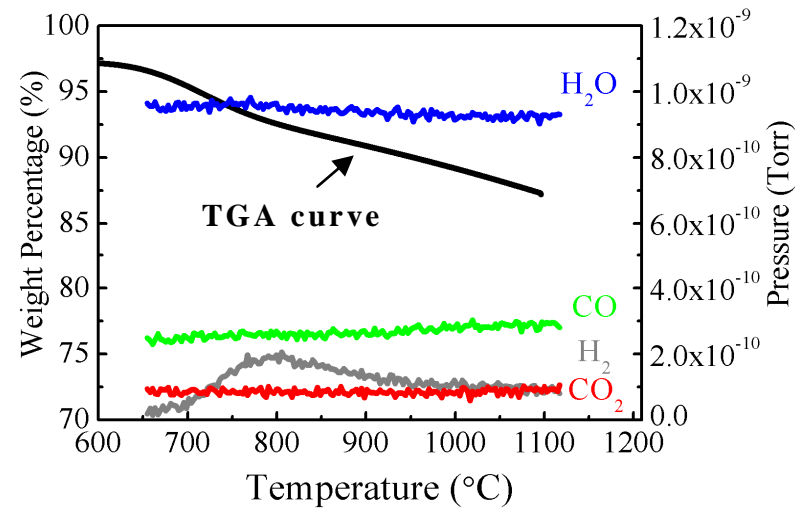

(b)

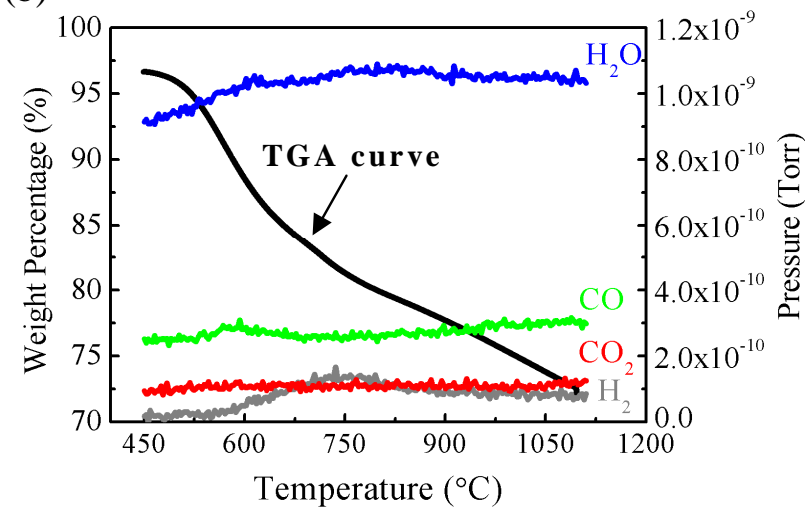

(d)

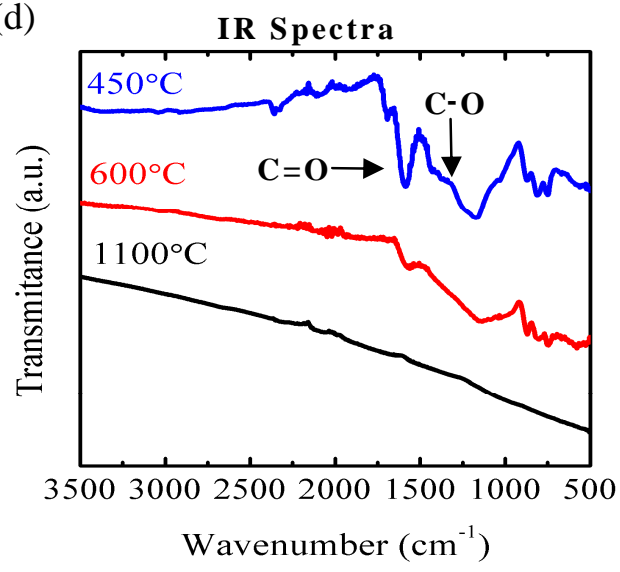

Figure 4. a) TGA and MS profiles of a) cellulose, b) sample pre-treated at $450{ }^{\circ} \mathrm{C}$, c) Sample pre-treated at $600^{\circ} \mathrm{C}$ d) IR spectra of carbon samples pyrolyzed at $450{ }^{\circ} \mathrm{C}, 600{ }^{\circ} \mathrm{C}$ and $1100{ }^{\circ} \mathrm{C}$

IR spectra provide insights on the activation mechanism as well. As Figure 4d shows, the pyrolysis at $1100{ }^{\circ} \mathrm{C}$ results in a very pure carbon, with almost no signals from oxygen-containing functional groups. Conversely, $\mathrm{P}-450$ exhibits peaks from a wide range of groups, including $\mathrm{C}=\mathrm{O}$ and 
$\mathrm{C}-\mathrm{O}$, and weaker signals of substituted aromatic rings, e.g., aldehydes and carboxylic acids. Similar $\mathrm{C}=\mathrm{O}$ and $\mathrm{C}-\mathrm{O}$ peaks still exist after a pre-treatment at $600{ }^{\circ} \mathrm{C}$ though the signals are considerably weaker. When integrating the IR and TGA/MS results, it is evident that as the pyrolysis temperature increases, the removal of oxygen and hydrogen groups results in the release of $\mathrm{H}_{2} \mathrm{O}$ that activates carbon, thus forming $\mathrm{H}_{2}$ as a by-product.

When a low flow rate is used, evolved activation gas molecules, e.g., $\mathrm{H}_{2} \mathrm{O}$, remain in the tube furnace for a longer time period, increasing the likelihood of the reaction in Eq. 3. The concept of using a low flow rate, and its consequence of inducing self activation can better be understood through the calculation of residence times $(\tau)$ of gas molecules in the reaction chamber. The residence time can be estimated through the equation

$$
\tau(\min )=\int_{x_{1}}^{x_{2}} \frac{A_{i}}{F_{0}} \cdot \frac{T_{\text {furnace }}(x)}{T_{\text {room }}} d x
$$

where $\tau$ is the residence time in min, $A_{i}$ is the cross-sectional area of the reaction chamber in $\mathrm{m}^{2}, F_{0}$ is the inlet flow rate in $\mathrm{m}^{3} \mathrm{~min}^{-1}, T_{\text {furnace }}$ and $T_{\text {room }}$ are the temperatures in Kelvin, and $x_{1}$ and $x_{2}$ are boundaries of the alumina crucible holding the filter paper. It is evident that the residence time is inversely proportional to the flow rate. Since the flow of Argon replaces the self-activation agents, such as $\mathrm{H}_{2} \mathrm{O}$ and $\mathrm{CO}_{2}$, it is reasonable to believe that these self-activation agents have very similar residence time as the Argon molecules flowing through the reaction chamber. Thus, a low flow rate of Argon results in higher residence times of self-activating agents, thereby increasing the likelihood of a self-activation reaction. As we can see from Figure 5 the residence times for lower flow rates are 10 to 20 times greater than those of higher flow rates; whereas the residence time at $1100{ }^{\circ} \mathrm{C}$ for a flow rate of $200 \mathrm{CCM}$ is of only 12 seconds, it jumps to nearly 4 minutes when the flow rate is lowered to $10 \mathrm{CCM}$. 


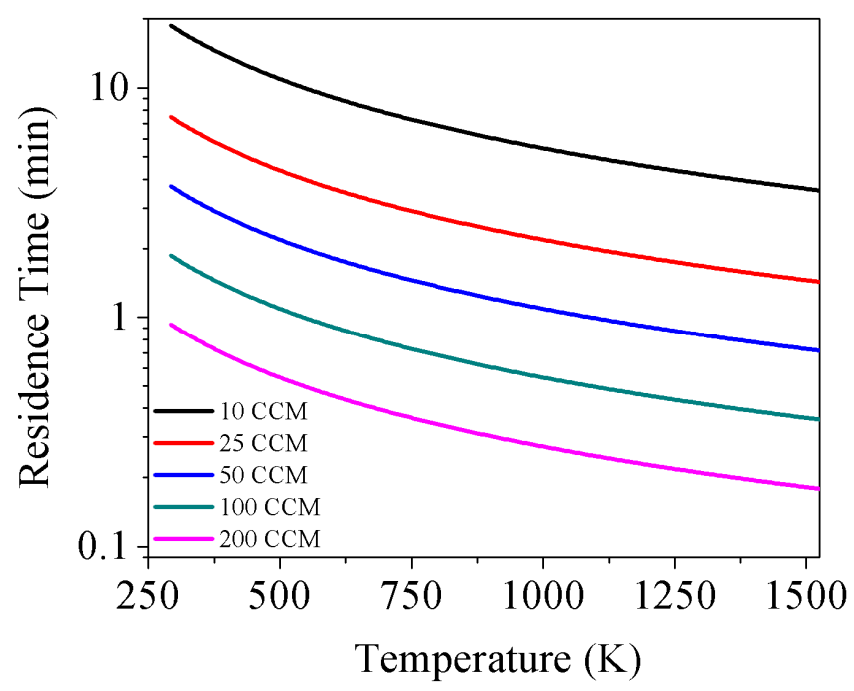

Figure 5 Residence times $(\tau)$ as obtained through the use of Eq. 6

We investigated the electrochemical properties of the C-10 of a surface area of $2,600 \mathrm{~m}^{2} / \mathrm{g}$ in symmetrical electrochemical capacitors (ECs). Cyclic voltammetry measurements are conducted at scanning rates of 20, 200, 500 and 1,000 $\mathrm{mV} \mathrm{s}^{-1}$. As shown in Figure 6a, C-10 exhibits excellent highrate capacitive behavior as the $\mathrm{CV}$ profile retains its rectangular shape even at a scanning rate of $1000 \mathrm{mV}$ $\mathrm{s}^{-1}$. From the EIS results, the Nyquist plot shows an intercept at the real impedance (Z') of $0.6 \Omega$, indicating a very low equivalent series resistance (ESR). An elongated 'semicircle' can be attributed to the widely distributed pore sizes in the structure. The Nyquist plot was simulated using two RC circuits connected in series and a restricted diffusion element M, as shown in Supplementary Figure S12. Galvanostatic charge/discharge of C-10 EC cells at a current rate of $1 \mathrm{~A} \mathrm{~g}^{-1}$ yields very symmetrical profiles, with a low voltage drop when switching from charge to discharge, thus corroborating the low 
ESR value seen from EIS. From the charge/discharge profiles, we observe a specific capacitance of $132 \mathrm{~F}$ $\mathrm{g}^{-1}$, which is well retained at over $100 \mathrm{~F} \mathrm{~g}^{-1}$ when the current rate is increased to $10 \mathrm{~A} \mathrm{~g}^{-1}$ (Figure 6c). After 6,000 cycles, a specific capacitance of $124 \mathrm{~F} \mathrm{~g}^{-1}$ remains, representing a $94 \%$ retention (Figure 6d). Despite the much more straightforward and inexpensive preparation, the performance of the nanoporous carbon from direct pyrolysis of cellulose is better than the conventional AC that is formed by activating commercially available petroleum-derived carbon by $\mathrm{CO}_{2}$. The $\mathrm{CO}_{2}$ activated carbon, which was measured to have a specific surface area of $2,400 \mathrm{~m}^{2} \mathrm{~g}^{-1}$ only exhibits a capacitance of $100 \mathrm{~F} \mathrm{~g}^{-1}$ at $1 \mathrm{~A} \mathrm{~g}^{-}$

\section{${ }^{1}$ (Supplementary Figure S13).}

(a)

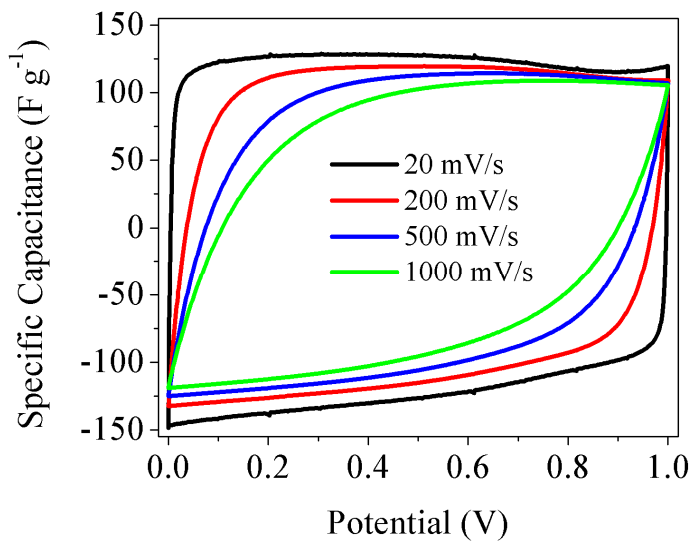

(c)

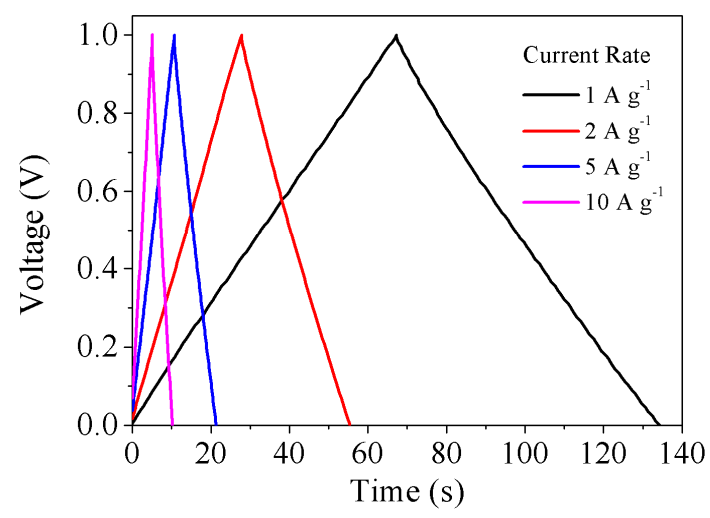

(b)

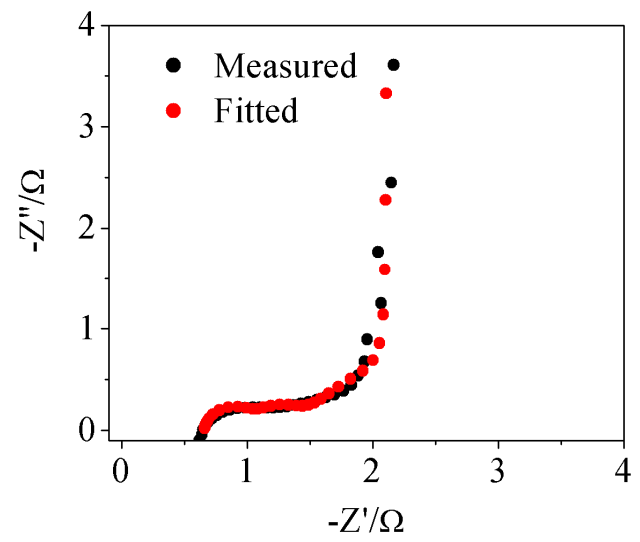

(d)

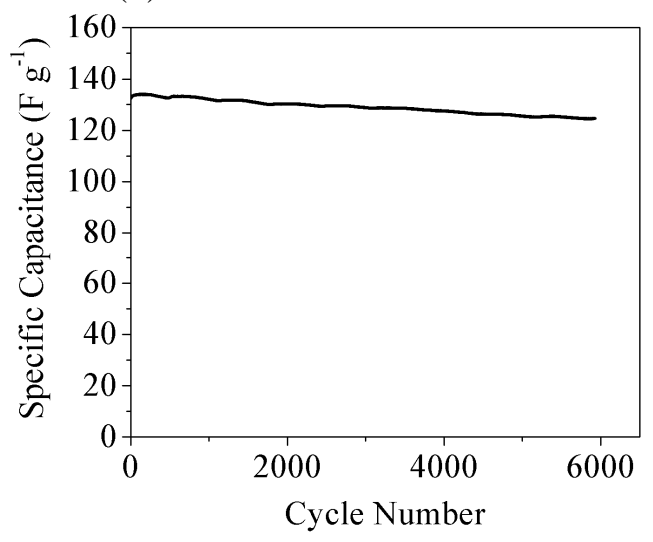

Figure 6 a) $\mathrm{CV}$ curves of ECs with voltage scanning rates ranging from $20 \mathrm{mV} \mathrm{s}^{-1}$ to $1,000 \mathrm{mV} \mathrm{s}^{-1} . \mathrm{b}$ ) Nyquist plot of a capacitor assembled with C-10 as electrodes. c) Galvanostatic charge/discharge profiles at a current rate ranging from $1 \mathrm{~A} \mathrm{~g}^{-1}$ to $10 \mathrm{~A} \mathrm{~g}^{-1}$. d) Galvanostatic cycling at a current rate of $1 \mathrm{~A} \mathrm{~g}^{-1}$. 


\section{Conclusion}

We demonstrate that high-surface-area nanoporous carbon can be synthesized in a single step pyrolysis reaction without the use of any chemical or physical activating reagents. We record strikingly linear relationships between the flow rates of Argon in the reaction and key properties of the resulting nanoporous carbon, including specific surface area/pore volume and degrees of short-range order. We identify that the high nanoporosity of the resulting carbon is due to the in-situ activation reactions between the resulting carbon and the gases, e.g., $\mathrm{H}_{2} \mathrm{O}$, that are evolved in situ during pyrolysis of cellulose over a wide range of temperatures. The residence time of evolving gases in the reaction chamber exerts a determining impact on the properties of the resulting nanoporous carbon. Through the use of a low flow rate, we are able to synthesize an $\mathrm{AC}$ that demonstrates a specific capacitance of $130 \mathrm{~F} \mathrm{~g}^{-1}$ at $1 \mathrm{~A}$ $\mathrm{g}^{-1}$, a performance better than that of conventional ACs that are synthesized through tedious processes. We expect that optimization of this one-step self-activation method will greatly lower the cost of ACs, which may have a profound impact on various fields that heavily rely on ACs. .

\section{Acknowledgments}

X.J. acknowledges the financial supports from Oregon State University. J.L. thanks the supports by the U.S. Department of Energy under Contract DE-AC0206CH11357 from the Vehicle Technologies Office, Department of Energy, Office of Energy Efficiency and Renewable Energy (EERE). Argonne National Laboratory is operated for the U.S. Department of Energy by UChicago Argonne, LLC, under contract DE-AC02-06CH11357. We are grateful to Professor Douglas A. Keszler for his assistance with the TGAMS measurements. We thank Dr. Peter Eschbach and Ms. Teresa Sawyer for the SEM measurements in OSU Electron Microscopy Facility funded in part by the National Science Foundation, the Murdock Charitable Trust and the Oregon Nanoscience and Microtechnology Institute (ONAMI). We are thankful to Mr. Joshua Razink for the TEM measurements at the Center for Advanced Materials Characterization at Oregon (CAMCOR). 


\section{References}

1. Perlack, R.D., L.M. Eaton, A.F. Turhollow Jr, M.H. Langholtz, C.C. Brandt, M.E. Downing, R.L. Graham, L.L. Wright, J.M. Kavkewitz, and A.M. Shamey, U.S. Department of Energy (2011).

2. Fargione, J., J. Hill, D. Tilman, S. Polasky, and P. Hawthorne, Science 319, (2008) 1235-1238.

3. Hoekman, S.K., Renewable Energy 34, (2009) 14-22.

4. $\quad$ Nigam, P.S. and A. Singh, Prog. Energy Combust. Sci. 37, (2011) 52-68.

5. Mettler, M.S., D.G. Vlachos, and P.J. Dauenhauer, Energ. Environ. Sci. 5, (2012) 7797.

6. Wang, J. and S. Kaskel, J. Mater. Chem. 22, (2012) 23710.

7. Candelaria, S.L., Y. Shao, W. Zhou, X. Li, J. Xiao, J.-G. Zhang, Y. Wang, J. Liu, J. Li, and G. Cao, Nano Energy 1, (2012) 195-220.

8. Xing, Z., B. Wang, W. Gao, C. Pan, J.K. Halsted, E.S. Chong, J. Lu, X. Wang, W. Luo, C.-H. Chang, Y. Wen, S. Ma, K. Amine, and X. Ji, Nano Energy 11, (2015) 600-610.

9. Radovic, L.R. and F. Rodriguez-Reinoso, Chem. Phys. Carbon (1997) 243-358.

10. Auer, E., A. Freund, J. Pietsch, and T. Tacke, Applied Catalysis A: General 173, (1998) 259-271.

11. Otowa, T., Y. Nojima, and T. Miyazaki, Carbon 35, (1997) 1315-1319.

12. Monser, L. and N. Adhoum, Sep. Purif. Technol. 26, (2002) 137-146.

13. Dias, J.M., M.C.M. Alvim-Ferraz, M.F. Almeida, J. Rivera-Utrilla, and M. Sánchez-Polo, J. Environ. Manage 85, (2007) 833-846.

14. Matranga, K.R., A.L. Myers, and E.D. Glandt, Chem. Eng. Sci. 47, (1992) 1569-1579.

15. Sircar, S., T.C. Golden, and M.B. Rao, Carbon 34, (1996) 1-12.

16. Rodriguezreinoso, F., M. Molinasabio, and M.T. Gonzalez, Carbon 33, (1995) 15-23.

17. Molina-Sabio, M., M.T. Gonzalez, F. Rodriguez-Reinoso, and A. Sepulveda-Escribano, Carbon 34, (1996) 505-509.

18. Maciá-Agulló, J.A., B.C. Moore, D. Cazorla-Amorós, and A. Linares-Solano, Carbon 42, (2004) 1367-1370.

19. Teng, H. and H.-c. Lin, AIChE J. 44, (1998) 1170-1177.

20. Pastor-Villegas, J. and C.J. Durán-Valle, Carbon. 40, (2002) 397-402.

21. Gergova, K., N. Petrov, and S. Eser, Carbon 32, (1994) 693-702.

22. Yang, K.B., J.H. Peng, C. Srinivasakannan, L.B. Zhang, H.Y. Xia, and X.H. Duan, Bioresour. Technol. 101, (2010) 6163-6169.

23. Sudaryanto, Y., S.B. Hartono, W. Irawaty, H. Hindarso, and S. Ismadji, Bioresour. Technol. 97, (2006) 734-739.

24. Ahmadpour, A. and D.D. Do, Carbon 35, (1997) 1723-1732.

25. Noked, M., A. Soffer, and D. Aurbach, J Solid State Electr. 15, (2011) 1563-1578.

26. Lin, Y.C., J. Cho, G.A. Tompsett, P.R. Westmoreland, and G.W. Huber, J. Phys. Chem. C. 113, (2009) 20097-20107.

27. Seshadri, V. and P.R. Westmoreland, J. Phys. Chem. A. 116, (2012) 11997-12013.

28. Lin, T., E. Goos, and U. Riedel, Fuel Process. Technol. 115, (2013) 246-253.

29. Wang, H., Z. Xu, A. Kohandehghan, Z. Li, K. Cui, X. Tan, T.J. Stephenson, C.K. Kingondu, C.M.B. Holt, B.C. Olsen, J.K. Tak, D. Harfield, A.O. Anyia, and D. Mitlin, ACS Nano. 7, (2013) 5131-5141.

30. Yoon, S. H., S. Lim, Y. Song, Y. Ota, W. Qiao, A. Tanaka, and I. Mochida, Carbon 42, (2004) 17231729.

31. Kierzek, K., E. Frackowiak, G. Lota, G. Gryglewicz, and J. Machnikowski, Electrochim. Acta 49, (2004) 515-523.

32. Munoz, Y., R. Arriagada, G. Soto-Garrido, and R. Garcia, J. Chem. Technol. Biotechnol. 78, (2003) 1252-1258. 
33. Tseng, R. L., J. Hazard. Mater. 147, (2007) 1020-1027.

34. Teng, H., T.-S. Yeh, and L.-Y. Hsu, Carbon 36, (1998) 1387-1395.

35. Laine, J., A. Calafat, and M. labady, Carbon 27, (1989) 191-195.

36. Puziy, A.M., O.I. Poddubnaya, A. Martínez-Alonso, F. Suárez-Garćia, and J.M.D. Tascón, Carbon 40, (2002) 1493-1505.

37. Yue, Z., C.L. Mangun, and J. Economy, Carbon 40, (2002) 1181-1191.

38. Ahmadpour, A. and D.D. Do, Carbon 34, (1996) 471-479.

39. Rodríguez-Reinoso, F. and M. Molina-Sabio, Carbon. 30, (1992) 1111-1118.

40. Nandi, M., K. Okada, A. Dutta, A. Bhaumik, J. Maruyama, D. Derks, and H. Uyama, Chem. Commun. 48, (2012) 10283-10285.

41. Zhang, T., W. Walawender, L. Fan, M. Fan, D. Daugaard, and R. Brown, Chem. Eng. J. 105, (2004) 53-59.

42. Luo, W., B. Wang, C.G. Heron, M.J. Allen, J. Morre, C.S. Maier, W.F. Stickle, and X.L. Ji, Nano Lett. 14, (2014) 2225-2229.

43. Lua, A.C., T. Yang, and J. Guo, J. Anal. Appl. Pyrolysis. 72, (2004) 279-287.

44. Lua, A.C., F.Y. Lau, and J. Guo, J. Anal. Appl. Pyrolysis. 76, (2006) 96-102.

45. Li, W., K. Yang, J. Peng, L. Zhang, S. Guo, and H. Xia, Ind. Crop. Prod. 28, (2008) 190-198.

46. Masoudi Soltani, S., S.K. Yazdi, and S. Hosseini, Applied Nanoscience 4, (2013) 551-569.

47. Kercher, A.K. and D.C. Nagle, Carbon 41, (2003) 15-27.

48. Warren, B.E., J. Chem. Phys. 2, (1934) 551-555.

49. Warren, B., Physical Review 59, (1941) 693-698.

50. Liu, Y.H., J.S. Xue, T. Zheng, and J.R. Dahn, Carbon 34, (1996) 193-200.

51. Buiel, E.R., A.E. George, and J.R. Dahn, Carbon 37, (1999) 1399-1407.

52. Dahn, J.R., T. Zheng, Y.H. Liu, and J.S. Xue, Science 270, (1995) 590-593.

53. Dahn, J.R., W. Xing, and Y. Gao, Carbon 35, (1997) 825-830.

54. Shi, H., J.N. Reimers, and J.R. Dahn, J. Appl. Crystallogr. 26, (1993) 827-836.

55. Yang, H.P., R. Yan, H.P. Chen, D.H. Lee, and C.G. Zheng, Fuel 86, (2007) 1781-1788.

56. Meng, A.H., H. Zhou, L. Qin, Y.G. Zhang, and Q.H. Li, J. Anal. Appl. Pyrolysis 104, (2013) 28-37.

57. Razvigorova, M., M. Goranova, V. Minkova, and J. Cerny, Fuel 73, (1994) 1718-1722.

58. Wojtowicz, M.A., R. Bassilakis, W.W. Smith, Y.G. Chen, and R.M. Carangelo, J. Anal. Appl. Pyrolysis. 66, (2003) 235-261.

59. White, J.E., W.J. Catallo, and B.L. Legendre, J. Anal. Appl. Pyrolysis. 91, (2011) 1-33.

60. Banyasz, J.L., S. Li, J. Lyons-Hart, and K.H. Shafer, Fuel 80, (2001) 1757-1763.

61. Zhou, X., M.W. Nolte, H.B. Mayes, B.H. Shanks, and L.J. Broadbelt, Ind. Eng. Chem. Res. (2014) 13274-13289.

62. Dong, C.Q., Z.F. Zhang, Q. Lu, and Y.P. Yang, Energy Convers. Manage 57, (2012) 49-59.

63. Isahak, W.N.R.W., M.W.M. Hisham, M.A. Yarmo, and T.-y. Yun Hin, Renew. Sustainable Energy Rev. 16, (2012) 5910-5923.

64. Collard, F.X. and J. Blin, Renew. Sustainable Energy Rev. 38, (2014) 594-608.

65. Chhiti, Y., S. Salvador, J.M. Commandré, and F. Broust, Fuel 102, (2012) 274-281. 


\section{Vitae}

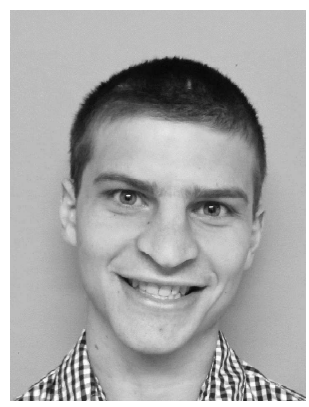

Clement Bommier is a Ph.D. candidate at Oregon State University. He received a dual bachelor's degree in chemistry and history from New York University in 2011, before beginning his graduate work under the supervision of Prof. Xiulei Ji in 2012. His current research interests are in carbon materials for energy storage, reaction mechanisms and computational material science.

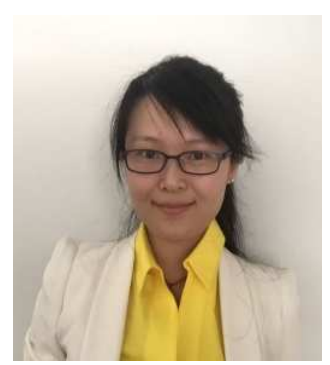

Dr. Rui Xu is a postdoctoral fellow at Argonne National Laboratory. She obtained her B.E. (2007) and M.S. (2009) in materials science and engineering from Tsinghua University in China, and her Ph.D. (2014) in materials science from University of Rochester. Her research is focused on advanced materials and cell configurations for high energy rechargeable battery systems, with an emphasis on nextgeneration Li-S battery development.

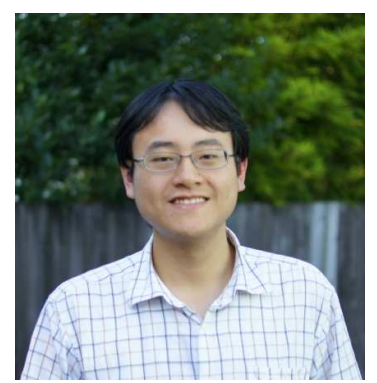

Dr. Wei Wang is an assistant professor at Fujian Institute of Research on the Structure of Matter (FJIRSM), Chinese Academy of Sciences and a courtesy faculty member in Department of Chemistry at Oregon State University. Wei received his B.Sc. degree in Material Science and Engineering from University of Science and Technology of China in 2008. He then joined Professor Douglas Keszler's group at Oregon State University obtained his Ph.D. in 2013. After completing his Ph.D study, Wei received the Post-doctoral Fellowship from Center for Sustainable Materials Chemistry (CSMC). He joined FJIRSM at the end of 2014 after finishing his postdoctoral research. Wei's research focuses on exploring aqueous chemistry and developing novel solution precursors for fabricating thin-film electronics. 


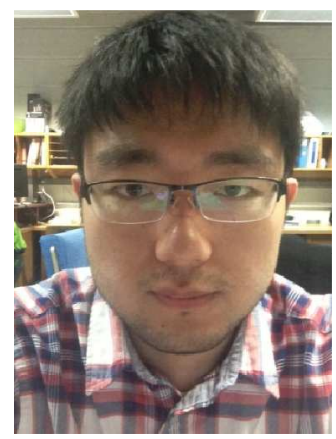

Xingfeng Wang received his B.Sc. degree from Jilin University in China in 2012. Since September 2012, he has been a Ph.D. student in Prof. Xiulei Ji's group in Oregon State University. His research interest focuses on nanomaterials, redox electrolyte and their applications in supercapacitors.

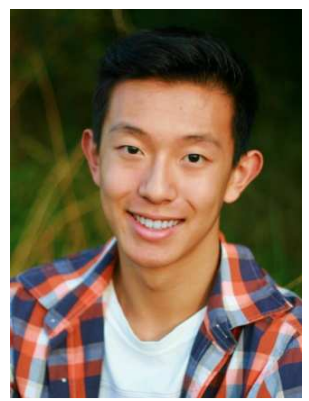

David Wen is a senior at Crescent Valley High School. In the summer of 2014, he was a summer worker in Dr. Ji's laboratory at Oregon State University. His research focus is in carbon materials for energy storage.

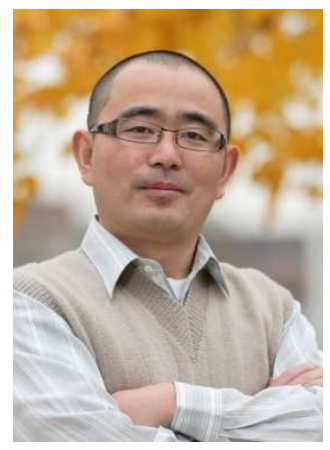

Dr. Jun Lu is a chemist at Argonne National Laboratory. His research interests focus on the electrochemical energy storage and conversion technology, with main focus on beyond Li-ion battery technology. Dr. Lu earned his bachelor degree in Chemistry Physics from University of Science and Technology of China (USTC) in 2000. He completed his Ph.D. from the Department of Metallurgical Engineering at University of Utah in 2009 with a major research on metal hydrides for reversible hydrogen storage application. He is the awardee of the first DOE-EERE postdoctoral fellow under Vehicles Technology Program from 2011-2013. Dr. Lu has authored/co-authored more than 100 peerreviewed research articles and has filed over dozen patents and patent applications. 


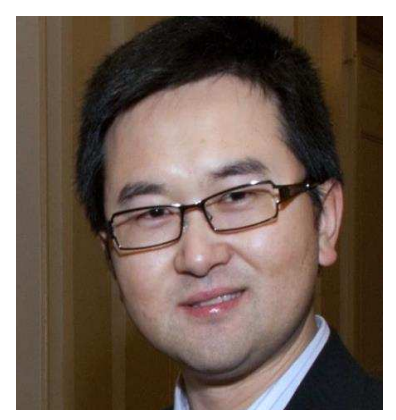

Dr. Xiulei (David) Ji received his B.Sc. Degree from Jilin University in 2003. He obtained his Ph.D. in 2009 from Professor Linda Nazar's group at the University of Waterloo. From 2010 to 2012, sponsored by the NSERC Postdoctoral Fellowship, Xiulei worked with Professor Galen D. Stucky for his postdoctoral studies at the University of California, Santa Barbara. Following his postdoctoral work, Xiulei became a faculty member at Oregon State University. His current research focuses on fundamental principles of materials chemistry for emerging energy storage devices. 


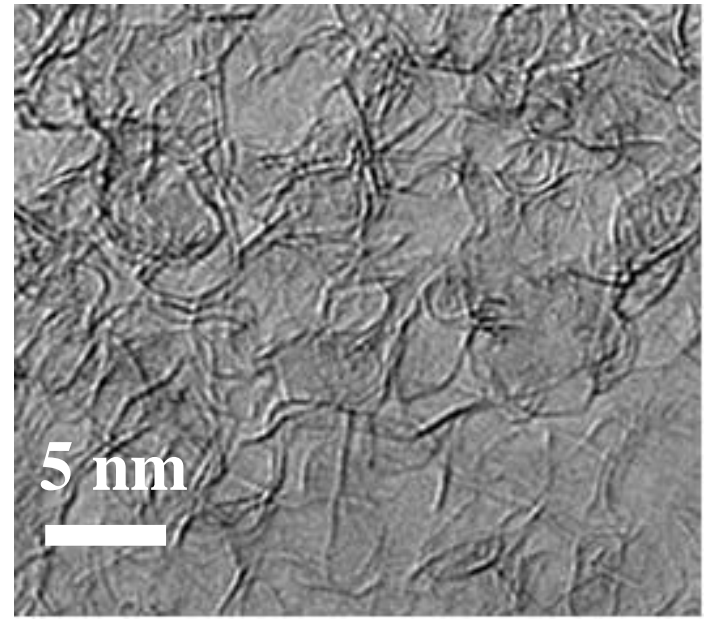

Direct pyrolysis of cellulose under Argon can surprisingly produce nanoporous carbon of surface areas as high as $2600 \mathrm{~m}^{2} / \mathrm{g}$. It is the very low flow rate of Argon of $10 \mathrm{CCM}$ during pyrolysis that facilitates the high nanoporosity. 